\title{
A PAISAGEM EM ARQUITETURA E URBANISMO: REMONTAR ÀS "NASCENTES" COMO OPÇÃO METODOLÓGICA
}

\author{
LANDSCAPE, ARCHITECTURE AND URBANISM: REASSEMBLING TO "SPRINGS" \\ AS A METHODOLOGICAL OPTION
}

Vladimir Bartalini*

\begin{abstract}
RESUMO
A revisão ou contestação dos preceitos da arquitetura e do urbanismo modernos trouxe, como contrapartida, no que diz respeito à profissão, ao ensino e à pesquisa em paisagismo, um incremento da atenção para aspectos sociais, ambientais ou culturais em sentido amplo. No entanto, não ensejou um impacto proporcional na abordagem da dimensão existencial e estética da paisagem. Procura-se, aqui, despertar a atenção para esta lacuna, apelando para textos de referência sobre esta dimensão, na suposição de que isto proporcione novas perspectivas para o ensino, a pesquisa e a atividade projetual em paisagismo.
\end{abstract}

Palavras-chave: Paisagem. Paisagismo. Ensino de paisagismo. Origens da paisagem.

\section{ABSTRACT}

The review of the precepts of modern architecture and urbanism brought, in return, with respect to the profession, teaching and research in landscaping, an increased attention to its social, environmental or cultural aspects in the broadest sense. However, it has not resulted in a proportionate impact in addressing the existential and aesthetic dimension of the landscape. What is sought here is to awake attention to this gap, appealing to reference texts about that overlooked dimension, in the assumption that this could provide new perspectives to teaching, research and design activity in landscaping.

Keywords: Landscape. Landscape architecture. Landscape architecture teaching. Origins of landscape.

\section{INTRODUÇÃO}

Mesmo que sem nome específico, ou sob o simples título "paisagismo", ou ainda sob as expressões "arquitetura da paisagem", "arquitetura paisagística", "desenho ambiental" ou tantas outras disseminadas mais recentemente, os assuntos referentes à paisagem têm sido objeto de ensino em arquitetura e urbanismo no Brasil desde a criação das primeiras escolas. Não custa lembrar que Grandjean de Montigny (17761850), responsável pelo primeiro curso regular de arquitetura na Academia Imperial, no Rio de Janeiro, também se dedicava, embora esporadicamente, à atividade paisagística (DOURADO, 2011).

* Graduado em Arquitetura e Urbanismo pela Faculdade de Arquitetura e Urbanismo da Universidade de São Paulo (FAUUSP). Mestre e doutor em Estruturas Ambientais Urbanas pela FAUUSP. Professor do Grupo de Disciplinas Paisagem e Ambiente (GDPA) e da Área de Concentração Paisagem e Ambiente do Curso de Pós-Graduação da FAUUSP.

bartalini@usp.br 
É também significativo que Lucio Costa - cuja passagem pela direção do Curso de Arquitetura da Escola Nacional de Belas Artes do Rio de Janeiro, no início da década de 1930, foi marcada por radical inflexão modernista nos seus rumos - tenha apoiado com entusiasmo a carreira do jovem Burle Marx, que se tornaria o nome mais proeminente do paisagismo brasileiro. Costa, de influência incontestável nos rumos da prática, do ensino e da pesquisa em arquitetura e urbanismo no Brasil, estava, como se sabe, sintonizado com os princípios condensados na Carta de Atenas - síntese das resoluções do IV Congresso Internacional de Arquitetura Moderna (CIAM), em 1933 - o que justifica revisitar tal documento, ainda que de modo sucinto, na versão que lhe foi dada por Le Corbusier em 1941, com o intuito de apontar as referências ali contidas sobre a paisagem, para em seguida tratar das primeiras manifestações de ruptura com suas prescrições.

A revisão das posturas da Carta de Atenas, que se deu no bojo da própria revisão do movimento moderno, atingiu o modo de abordar a paisagem, com reflexos na profissão e no ensino do paisagismo. Resumidamente, pode-se identificar como pontos característicos desta mudança a atenção para as particularidades, não só dos lugares e das paisagens, como também dos diferentes valores e percepções dos que os usufruem. À maior importância atribuída aos aspectos de uso e às chamadas funções sociais dos espaços livres correspondeu a preterição, ou indiferença, ou, ainda, certo desconforto no lidar com a natureza estética da paisagem.

A ampliação que a noção de paisagem conheceu por conta da diversidade de contribuições disciplinares que chegaram em seguida à arquitetura e ao urbanismo, vindas notadamente da ecologia, da biologia, das ciências da natureza de modo geral, mas também da geografia humana, conduziu à diluição, se assim se pode dizer, da própria acepção do termo "paisagem". Evidentemente, estas mudanças tiveram implicações no ensino do paisagismo sem que, mais uma vez, levassem com igual vigor à indagação a respeito de uma das características mais fundamentais da paisagem, ou seja, sua origem estética, de modo a trazer novos ares ao ensino e à atividade projetual.

A justificativa para este voltar os olhos às "nascentes" da paisagem vem do próprio esquecimento, ou, em hipótese mais favorável, do seu esmaecimento nas abordagens normalmente adotadas em nossas escolas. A busca de alento para o ensino e a pesquisa é o principal objetivo destas páginas, e o procedimento utilizado para tanto é o de expor uma trajetória dos enfoques mais influentes no que diz respeito ao entendimento da paisagem, trazendo à tona alguns textos fundamentais que prospectam a paisagem em seu nascedouro.

Entende-se que a retomada de textos como Filosofia da paisagem, de Georg Simmel, Paisagem: função do estético na sociedade moderna, de Joachim Ritter, e $\mathbf{O}$ homem e a Terra, de Eric Dardel, escritos em diferentes momentos, possa contribuir metodologicamente para o ensino e a pesquisa em paisagismo.

\section{CERTA HEGEMONIA}

Não é de se estranhar a consideração da paisagem em Congressos Internacionais de Arquitetura Moderna, dominados que eram pelos franceses. De fato, era forte o pres- 
tígio da geografia de Vidal de La Blache, firmemente fundada na paisagem e divulgada através de vários livros, dentre os quais, Tableau de la géographie de la France, publicado em 1908, no qual estão descritas as principais feições do território francês, sínteses distintivas produzidas pelas ações humanas impressas em determinado suporte físico. Compreende-se, assim, por que os delegados do IV CIAM, na análise que realizaram de várias cidades de diversos continentes, dispunham de "[...] um mapa em escala 1:50.000 assinalando a cidade com seu entorno imediato, as ligações suburbanas e as características do relevo e da paisagem." (SCHERER, 1993).

Em outro domínio e em outra escala, mas também conhecendo ampla difusão, há as propostas de Jean Claude Nicolas Forestier, que, em seu Grandes villes et systèmes de parcs, de 1908, movido pela intenção de continuar a obra iniciada por Haussmann e Alphand, incluiu "[...] as grandes reservas e as paisagens [...]" como primeiras categorias do sistema de parques por ele idealizado. (FORESTIER, [1908]1997).

Estas notas sobre a paisagem corroboram a afirmação de que na Carta de Atenas:

[...] excetuados os tópicos relativos ao patrimônio histórico - introduzidos nas constatações por solicitação dos delegados italianos ao IV Congresso - não trazia nada de novo [...] (SCHERER, 1993).

Eram antes uma sinopse do urbanismo racionalista e o resultado de "[...] contribuições de mais de um século de arquitetura, incluindo desde as propostas do socialismo utópico até as da Bauhaus, passando por Morris, Howard, Tony Garnier." (SCHERER, 1993).

Há também reflexos, na Carta..., de uma antropogeografia oitocentista atenta às influências da natureza na constituição das sociedades e da própria psicologia humana presente nas "[...] generalidades [...]" que precedem as "[...] críticas e remédios [...]" ao estado atual das cidades, tratado na segunda parte da Carta..., como se pode constatar nestas passagens:

A geografia e a topografia desempenham um papel considerável no destino dos homens [...] Se o montanhês desce voluntariamente para a planície, o homem da planície raramente sobe os vales e dificilmente transpõe os desfiladeiros [...] A proporção dos elementos água e terra [...] conforma, ela também, atitudes mentais que se inscreverão nos empreendimentos e encontrarão sua expressão na casa, na aldeia ou na cidade. (LE CORBUSIER, 1993).

No item 14, referente à habitação, na seção Críticas e remédios, Le Corbusier (1993) conclui: "[...] as aspirações instintivas do homem o induzem, sempre que seus recursos the permitem, a procurar condições de vida e uma qualidade de bem-estar cujas raízes se encontram na própria natureza."

Não é simples resumir a posição de Le Corbusier com relação à paisagem. Em que pese a sua sensibilidade paisagística (portanto, acolhedora da diversidade) - já evidente nas descrições de A viagem do Oriente, de 1911 - preconizou no seu Urbanisme, de 1925, naquilo que concerne à paisagem urbana, a pureza decorrente da ordem geomé- 
trica. Deu, sim, importância à paisagem natural, aos relvados, às massas arbóreas na cidade, mas como presenças dispersas ou mesmo como pano de fundo para o destaque da "[...] geometria transcendente [...]" das intervenções arquitetônicas. (LE CORBUSIER, 1925, p. 166). Admitiu alternativas à precisão da linha reta, mas com condições:

Em terreno acidentado, a curva tem direitos a priori, uma vez que se trata, serpenteando, de obter rampas regulares; o pitoresco torna-se inevitável, e o problema arquitetônico consiste então em disciplinar a desordem imanente em favor de uma unidade sempre indispensável a todo sentimento de bem-estar e a toda intenção estética. (LE CORBUSIER, 1925, p. 201).

Por mais que se o associe à impessoalidade, Le Corbusier considerou a emoção, que nos tocaria:

[...] se esta linha que perfila a cidade sobre o céu fosse pura e se experimentássemos por ela a presença de uma potência ordenadora [...] Por ela é-nos permitido ordenar com amplidão a paisagem urbana. E isto é capital. Repito que esta linha sobre o cév é determinante da sensação. (LE CORBUSIER, 1925, p. 220).

Tal pureza se atingiria se os edifícios com coberturas planas fossem dispostos de forma a estender o horizonte ora à direita, ora à esquerda, formando reentrâncias e saliências, com o que se criaria, também, "[...] uma viva e monumental paisagem urbana." Assim procedendo, as árvores poderiam ser introduzidas na cidade:

[...] No momento, deixando de lado os fatores de higiene, pode-se admitir que, esteticamente falando, o encontro dos elementos geométricos dos edifícios com os elementos pitorescos da vegetação constitui um conjunto suficiente e necessário à paisagem urbana. (LE CORBUSIER, 1925, p. 224).

Pode-se dizer que a paisagem idealizada por Le Corbusier implicava o contraste entre a ordem geométrica presente na arquitetura e o caráter menos controlável dos elementos naturais. Em outras passagens, ele deixa transparecer suas referências formais em relação aos vastos espaços que entremeiam os edifícios:

Entramos pelo jardim inglês [...] de repente estamos aos pés dos primeiros arranha-céus. Entre eles não há a estreita fresta de luz de uma New York angustiante, mas o espaço verde. (LE CORBUSIER, 1925, p. 168).

$\bigcirc$ "jardim inglês" ao qual o autor se refere é, decerto, o jardim "paisagístico", fruto de uma lenta depuração do gosto no decorrer dos setecentos. É curiosa esta remissão a um modelo ancestral da parte de um inovador tão radical, como também chama atenção o fato da Bauhaus, atuante em tantos aspectos que envolviam o desenho do espaço humano - e tão influente, mundialmente, na direção do ensino da arquitetura 
- não ter se pronunciado quanto às questões da paisagem ou dos jardins.

A investigação de novos valores perceptivos associados à experiência da paisagem deveu-se, em grande parte, no período em que a hegemonia dos princípios da Carta de Atenas era inabalável, à produção de paisagistas não europeus - notadamente os americanos James Rose, Thomas Church e Garrett Eckbo, o mexicano Luis Barragán e o brasileiro Burle Marx - ainda assim voltada predominantemente aos domínios privados ou a fragmentos isolados no ambiente público urbano.

Sabe-se que, por mais influentes que tenham sido as propostas corbusianas nos rumos do pensamento urbanístico, a sua realização na prática foi limitada, resumindo-se a algumas experiências parciais de reconstrução urbana no pós-guerra e à construção de poucas cidades, com destaque para Brasília. É como se, em vista das dificuldades de concretização dos preceitos em sua totalidade, o urbanismo só os aplicasse na medida do possível, e sempre setorialmente. Assim, no que se refere às áreas verdes urbanas, assiste-se à formulação e implantação de sistemas de parques, mas, pode-se afirmar, sobretudo como resposta a um programa, o que encontrará ressonância na proliferação de propostas de índices de verde por habitante e de "sistemas" de áreas verdes ou de espaços livres urbanos ou regionais.

\section{MUDANÇAS DE RUMO}

Foi nas fissuras do bloco modernista, expostas no IX CIAM, em 1953, que a preocupação com as singularidades sociais e culturais dos lugares - nas quais se incluem as paisagens - encontrou condições para firmar-se, desembocando na publicação, já nos anos 1960, de títulos que contemplavam parâmetros para a abordagem dos aspectos perceptivos da paisagem no meio urbano. Faz-se aqui referência às obras The image of the city, de Kevin Lynch (1960 [1997]), e Townscape, de Gordon Cullen (1961) que ganhou o revelador subtítulo de "tratado de estética urbanística" na tradução para o espanhol - e à divulgação mais ampla das ideias de Camillo Sitte contidas em Der Städtebau nach seinen Künslerische Grundsätzen, de 1889, sobre a construção das cidades segundo "princípios artísticos", graças à sua tradução para o inglês (1965).

Longe da pretensão de esgotar o assunto, não poderia deixar de mencionar, neste rápido painel, o artigo The social function of open spaces, de Lewis Munford, publicado em 1960. O próprio título revela o teor das ideias de Munford a respeito destes espaços. autor, depois de reconhecer o papel dos grandes parques paisagísticos, "[...] mais ou menos no estilo promovido pela aristocracia nas suas propriedades rurais [...]" no combate ao "[...] congestionamento e à desordem crescentes da cidade [industrial] [...]" observa que a maior parte das cidades é tão deficitária em espaços livres:

[...] que estes passaram a ser tratados como se seu valor fosse diretamente proporcional à sua área - sem muita atenção à sua beleza formal, sua acessibilidade, sua frequência de uso, seu efeito alterador da experiência de viver o urbano. (MUNFORD, 1960, p. 1). 
Sem deixar de afirmar a importância da "[...] função higiênica [...]" dos espaços livres, Munford (1960, p. 2-3) exorta a considerar o seu "papel social" e antevê no horizonte uma "[...] civilização do jardim [...]", passível de ser atingida se nos dedicarmos a "[...] retomar (re-posses) e reorganizar toda a paisagem." Reconhece que:

[...] chegou a hora do landscape design conceber alternativas aos clichês clássicos e românticos do passado, e aos clichês ainda mais estéreis dos "devoradores de espaço" que acabariam por aniquilar todos os recursos estéticos da paisagem [...] (MUNFORD, 1960, p. 2-3).

A solução de Munford passa pelo estabelecimento de uma matriz verde (que abarca o urbano e o regional, o público e o privado) formada por espaços abertos destinados ao lazer, porém não mais realizado em um ou outro parque paisagístico ou reserva selvagem, e sim em espaços voltados "[...] à agricultura, à horticultura e às respectivas indústrias rurais [...]", de modo que, "[...] para os lazeres de fim de semana, toda a paisagem se torne, de fato, o parque paisagístico." (MUNFORD, 1960, p. 4). O autor deixa em aberto as qualidades estéticas desta nova paisagem (embora pareçam persistir, pressupostas, as qualidades que o senso comum atribui aos parques paisagísticos e às paisagens rurais), atendo-se a anunciar possibilidades:

[...] há lugar para toda uma experimentação nova e para projetos audaciosos, que se afastam tanto dos modelos tradicionais como dos que se tornaram clichês formais contemporâneos. Nesse campo, cada cidade, com base em sua própria paisagem e cultura, deve oferecer uma resposta diferente [...] (MUNFORD, 1960, p. 4).

Esta breve e incompleta retrospectiva de ideias divulgadas sob a égide do urbanismo, ainda que originadas de reflexões e experimentos anteriores à constituição do urbanismo enquanto disciplina, tem sua justificativa na forte ascendência que, direta ou indiretamente, exerceu no ensino e na pesquisa relacionados ao paisagismo em nossas escolas de arquitetura.

Ainda dentre os autores que escreveram neste período do pós-guerra, mas já assumidamente situado no campo do paisagismo, destaca-se o nome de Garrett Eckbo, um dos pioneiros do paisagismo moderno norte-americano (sua atuação profissional remonta à década de 1930) e, também, professor do Departamento de Landscape Architecture da Universidade de Berkeley, na Califórnia. Por meio dos livros de sua autoria, Eckbo divulgou não só os conhecimentos empíricos decorrentes de décadas de exercício profissional como landscape architect, mas também as orientações gerais que julgava fundamentais para a área profissional correspondente cumprir seu papel.

Com o intuito de definir o que é landscape design, Eckbo faz em seu primeiro livro, Landscape for living, de 1950, uma breve incursão pela história para situar as bases do projeto paisagístico no século XVIII, justamente quando os jardins saltam os muros e ganham a paisagem, ou melhor, quando a paisagem, enquanto natureza idealiza- 
da, invade os jardins. Não se trata mais, portanto, de atuar exclusivamente nos limites estabelecidos pela encomenda: "[...] mesmo que sempre trabalhemos em quintais, temos que estar conscientes do mundo ao qual estes quintais pertencem [...]", ou seja, "[...] o mundo em que vivemos [...]", por sinal um dos títulos da seção Background, que abre o livro. Assim sendo: "[...] o paisagismo (landscape design), como a arte que dá expressão física direta às relações entre o homem [...] e a paisagem do mundo em que ele vive, não tem limites, exceto onde o homem deixa de transformar a paisagem." (ECKBO, 1950, p. 31-32).

Às declarações mais básicas e de ordem geral que integram a primeira seção do livro, sucedem-se considerações que Eckbo enfeixa sob o nome de "Teoria". Na verdade, são abordados os elementos em que houve por bem decompor a paisagem - o espaço (físico) e as pessoas, os materiais, o solo, as rochas, a água, as plantas, as construções - com uma intenção pragmática, visando à sua aplicação no projeto de paisagismo. Coerentemente, a seção seguinte, que recebe o nome de "Prática", é dedicada aos jardins, parques, espaços associados a edifícios públicos, conjuntos de casas.

$\bigcirc$ livro seguinte de Eckbo vem a público em 1956 com o título The art of home landscaping. Como o próprio nome indica, é um livro especialmente voltado ao tratamento paisagístico do espaço residencial, o que não impede Eckbo de reafirmar, no prefácio, a abrangência de seu entendimento da função e do objeto do paisagismo:

A primeira função social do arquiteto paisagista é sua habilidade em juntar todos os complexos e desconectados elementos do espaço exterior em unidades reconhecíveis de uma paisagem útil e agradável. (ECKBO, 1956. Não paginado.)

Em Urban landscape design, de 1964, Eckbo segue um esquema semelhante ao do livro precedente: uma preleção geral acompanhada de exemplos práticos, só que, agora, referentes ao meio urbano, levando em conta, portanto, as vias, as infraestruturas, as áreas de recreação, além de escadas, muros, plantas, água, rochas, abrigos. Volta às afirmações já presentes nas obras anteriores de que o landscape design deve "[...] considerar toda a paisagem [...]", aplicando os processos gerais de projeto aos projetos específicos, sejam eles de jardins residenciais, de parques públicos, de praças ou de qualquer outro espaço na escala da cidade ou mesmo da região. A paisagem, reassevera Eckbo, é:

[...] o complexo total de elementos físicos em uma dada área [...] é o mundo que nos envolve. É tudo o que vemos ou sentimos onde quer que estejamos [...] seus limites são o da visão humana e do movimento humano [...] se estende de oceano a oceano [...] Ela não só é fisicamente indivisível, mas [...] é de fato inseparável da paisagem social - pessoas em relações. (ECKBO, 1964, p. 17).

Cabe aqui ressaltar, de passagem, a diferença que separa esta afirmação de Eckbo quanto à indivisibilidade da paisagem, daquela de Georg Simmel (1988), que vê na emergência da paisagem justamente o contrário: a subtração de um "pedaço" ao continuum indivisível da natureza, conducente ao problema de como resolver a sua re-união. 
Em 1969, Eckbo lançou o livro The landscape we see, com estrutura semelhante à dos anteriores, na medida em que nele se intercalam declarações de princípios, definições e considerações de ordem prática. $\bigcirc$ autor volta a afirmar que o espaço aberto - ruas, áreas entre edificações e áreas desocupadas em geral - é "[...] o domínio normal da landscape architecture, e que o seu objetivo é: [...] estabelecer continuidade, conexões ou relações entre as edificações, o terreno e a paisagem circundante [...]" (ECKBO, 1969, p. 97).

Não só mantém suas posições prévias, mas também investe no sentido de ampliar o âmbito de atuação do arquiteto paisagista ao declarar que o landscape design:

[...] tende a se tornar o traço de união entre as outras artes do espaço e o mundo em geral, a continuidade da paisagem total [...] a landscape architecture é o processo de projeto que torna possível controlar completamente a qualidade dos nossos jardins, parques, bairros, comunidades e regiões. (ECKBO, 1969, p. 97-98).

A atenção aqui dispensada a Eckbo é proporcional à força dos preceitos por ele divulgados na orientação profissional de alguns dos mais expressivos nomes do paisagismo no Brasil e à sua incidência nas atividades práticas relacionadas às disciplinas de paisagismo em nossas escolas de arquitetura, particularmente em São Paulo.

É importante, por isso, observar como a paisagem comparece nos escritos de Eckbo. O seu objeto de reflexão não parece ser propriamente a paisagem, e sim o landscape design. A paisagem é, antes, o campo sobre o qual atua; ela é um dado de fundo. Assim sendo, basta-lhe defini-la, num primeiro momento, como "[...] o complexo total de elementos físicos em uma dada área." (ECKBO, 1964, p. 3). No entanto, neste "complexo total" estão implícitos alguns valores, pois, quando toca na questão da "destruição da paisagem", refere-se à "esterilização" provocada pela degradação do ambiente natural ou rural anterior à urbanização. Mais tarde, porém, expande o conceito, formulando a paisagem como possibilidade de unir sociedade e natureza (o que é retomado, aliás, em seu último livro, People in a landscape, que veio a público em 1998):

[...] Por paisagem entendo tudo o que nos envolve, onde quer que estejamos. Isto inclui não só todos os elementos físicos - terra, água, atmosfera, edifícios, árvores, ruas, carros - mas também os costumes, leis, tradições, permissões, proibições, e atitudes que os antropólogos e os sociólogos denominam cultura. A paisagem física é um produto dos processos da natureza e da cultura humana, combinados em proporções variadas [...] (ECKBO, 1969, p. 3).

\section{DILUIÇÃO DOS SENTIDOS}

A tal expansão da ideia de paisagem corresponde também à sua diluição. Resta, desta maneira, aplicar-se aos modos de operar sobre ela nas mais variadas escalas e com os mais variados escopos; eventualmente, protegê-la, mas não mais interrogá-la. De fato, toda uma produção recente e significativa, resultante de pesquisas na área do 
paisagismo no Brasil - voltadas a projetos e à história do paisagismo, ao planejamento paisagístico ou, ainda, a sistemas de espaços livres (aliás, dotada de grande diversidade de enfoques, do morfológico ao antropológico, do sociológico ao ecológico) usa o termo paisagem numa acepção genérica, difusa, permitindo, a depender do caso, sua substituição por ambiente, espaço ou natureza.

mesmo ano de 1969, no qual Eckbo publicou The landscape we see, foi também o da primeira edição de Design with nature, de lan McHarg. Como observou Lewis Mumford na apresentação do livro, estava-se ali não mais diante da obra de um town planner ou de um landscape architect, mas de um ecological planner. Vivia-se o início das preocupações ambientais que ocupariam as atenções de planejadores, arquitetos, paisagistas, artistas e políticos daí em diante.

O livro de McHarg abriu uma perspectiva na área do paisagismo que refletiu no seu ensino e na sua pesquisa, ensejando o contato com tantas outras disciplinas, como a ecologia e a geografia, em suas respectivas ramificações e, mais tarde, com a engenharia e as ciências ditas ambientais. É notável que a palavra paisagem esteja praticamente ausente em Design with nature, e, quando ela comparece na área de arquitetura e urbanismo nos anos subsequentes, já vem carregada dos sentidos emprestados da ecologia e de um setor da geografia, quando não utilizada no sentido genérico já apontado. Os objetivos e procedimentos adotados entre nós nesta linha parecem guardar certo parentesco com aqueles do funcionalismo, ainda que, a rigor, a proeminência da função tenha sido transferida ao processo.

Há, então, justamente, que se considerar toda a contribuição proveniente de outras áreas (interessa aqui, sobretudo, a geografia) quando se trata de reconhecer o modo como as questões da paisagem foram (e são) tratadas nas escolas de arquitetura. Faz sentido afirmar que muito da afinidade entre a arquitetura, o urbanismo e a geografia reside no lugar privilegiado atribuído ao olhar. De fato, desde Alexandre von Humboldt, passando por Paul Vidal de La Blache, Jean Brunhes e chegando mesmo a Pierre George, formou-se uma tradição, com firme incidência no ensino brasileiro, que fez da paisagem o objeto por excelência da geografia, ao qual correspondeu um conceito de fisionomia e um método de observação e leitura envolvendo dois momentos: o olhar analítico, que distingue "[...] os diferentes elementos particulares, naturais e humanos que compõem uma paisagem dada [...]", como numa "[...] dissecação [...]", e o olhar sintético, que restitui o conjunto da paisagem. (BESSE, 2006, p. 74).

A trajetória do pensamento geográfico registra inflexões importantes nesta tradição baseada no contato direto com a paisagem sob o comando da visão. Numa determinada tendência da chamada geografia pragmática, o empirismo da observação visual é substituído pelo das estatísticas, dos modelos, dos sistemas. Nela, a paisagem é abstraída. Mas, ainda dentro do pragmatismo, abriram-se outras perspectivas, como a da geografia da percepção ou comportamental, que se interessa pela "[...] valorização subjetiva do território, a consciência do espaço vivenciado, o comportamento em relação ao meio [...]" (MORAES, 1982, p. 100-106). É possível reconhecer traços desta abordagem em várias pesquisas desenvolvidas na área de paisagem em escolas 
de arquitetura, cabendo observar, como já dito, que nestes casos é muito comum os conceitos de espaço, de meio ambiente e de paisagem se confundirem.

movimento de renovação do pensamento geográfico recebeu também um significativo aporte advindo de uma ala da geografia que, pelo posicionamento teórico de seus principais representantes, adquiriu o adjetivo de "crítica" (MORAES, 1982). Milton Santos é o nome mais notável desta vertente no Brasil e sua ascendência manifesta-se claramente em trabalhos de pesquisa abrigados nas áreas vinculadas à paisagem, em escolas de arquitetura, desde o final dos anos 1970. Para atender a uma "[...] necessidade epistemológica [...]", Santos opera a distinção entre paisagem e espaço:

A rigor, a paisagem é apenas a porção da configuração territorial que é possível abarcar com a visão [...] se dá como um conjunto de objetos reais-concretos [...] a paisagem existe através de suas formas [...] (SANTOS, 2008, p. 103-104).

Ainda que reconheça a importância das formas, ressalva que "[...] só por sua presença, os objetos técnicos não têm outro significado senão o paisagístico." (SANTOS, 2008, p. 105). É preciso um conteúdo social que os anime. No esforço analítico de distinguir paisagem e espaço, cabe àquela o papel de matéria inerte, destituída de vida.

Já na ótica fenomenológica, esta distinção não faz sentido. Deve-se, no entanto, assinalar as diferenças que subsistem na vertente da geografia que assume a paisagem não como pura objetividade, mas, antes, "[...] introjetada no sistema de valores humanos, definindo relacionamentos complexos entre as atitudes e a percepção sobre o meio." (RIBEIRO, 2007, p. 24).

A simples comparação entre Topofilia, de 1974, talvez o livro mais divulgado do geógrafo Y-fu Tuan aqui no Brasil, e O homem e a Terra, do também geógrafo Eric Dardel, publicado em 1952, deixará clara a diferença de objetivos e abordagens. Jean-Marc Besse ressalta com propriedade o que especifica o enfoque de Dardel:

Esta relação com a Terra não significa um sombrio e, afinal, insignificante enraizamento num lugar (não é assim que as coisas se apresentam para Dardel). Ela exprime antes a possibilidade de inscrever a liberdade humana em lugares que se tornarão como que sua marca, e da qual a paisagem será a manifestação. (BESSE, 2006, p. 93).

Não se pode deixar de observar, por fim, o ofuscamento das questões ligadas à arte ao tratar-se de paisagem nas escolas de arquitetura e urbanismo. Se num primeiro momento podia-se falar em "arte dos jardins", em apreciar o "sentimento de uma paisagem" - ou atentar, de um modo geral, para sua dimensão estética -, a partir da emergência das questões sociais e ambientais, com impacto suficiente para ensejar o neologismo socioambiental, o assunto perdeu interesse. Nos casos mais favoráveis passou a ocupar posição secundária, quando não, convencional. Em boa parte da produção bibliográfica concernente ao paisagismo, ele é limitado a uma seção, ou a um ou outro parágrafo. Foi acolhido, no entanto, em sua atual complexidade, na área das artes, seja na reflexão teórica, seja na produção artística propriamente dita. 
A menção aos artistas da land art e também aos anteriores e posteriores a ela, "teóricos" e "práticos" ao mesmo tempo, que se abriram para a paisagem, é obrigatória aqui - com repercussões que ainda ressoam.

Pode-se dizer que, ao espraiamento das acepções de paisagem, seguiu-se o enfraquecimento do seu significado. Enfim, a que nos referimos quando, no âmbito da arquitetura e urbanismo, dizemos paisagem?

\section{UM REMONTAR ÀS "NASCENTES"}

que foi exposto até aqui teve a intenção de apontar a importância de prospectar as "fontes" da paisagem não com o objetivo de empreender uma retrospectiva histórica para chegar à origem de um conceito, mas antes de facear a sua natureza e apontar para o seu papel social. Quando se pressente o risco de automatizar julgamentos, de calcificar conceitos e os modos de operá-los, convém voltar-se às nascentes. Neste sentido, ganham proeminência os ensaios de Georg Simmel, Filosofia da paisagem, de 1913, e de Joachim Ritter, Paisagem: função da estética na sociedade moderna, de 1963, que buscam a paisagem justamente no seu nascedouro.

Simmel (1988, p. 231) parte da constatação de que observar os mais diversos objetos que se apresentam à visão - árvores, água, colinas, casas, nuvens, ruas -, bem como as mais sutis variações de luz, "[...] não basta para termos a consciência de ver uma 'paisagem'." Para que haja efetivamente paisagem, continua ele: "[...] a consciência deve apreender, além dos elementos, um novo conjunto, uma nova unidade, não ligados aos significados particulares de cada elemento, nem compostos mecanicamente da sua soma."

O seu ensaio é justamente uma tentativa de interpretar o processo que engendra esta unidade à que se dá o nome de paisagem. Para tanto, Simmel (1998, p. 238) propõe uma analogia com o nascimento de uma obra de arte: "[...] ali onde vemos realmente uma paisagem e não mais um aglomerado de objetos naturais, vemos uma obra de arte in statu nascendi." Nesta circunstância, "[...] um certo conceito unificador [...]" envolve a matéria para imprimir-lhe uma forma. $\bigcirc$ fator essencial para esta unificação é identificado por Simmel como a Stimmung, palavra que pode ser aproximadamente traduzida por "atmosfera", ou "estado de alma".

Uma dificuldade que Simmel levanta é a da "localização" da Stimmung:

[...] em que medida a Stimmung se funda objetivamente na paisagem, uma vez que ela é um estado psíquico e reside no reflexo afetivo do espectador e não nas coisas exteriores, desprovidas de consciência? (SIMMEL, 1988, p. 241).

E mais: sendo a Stimmung o fator essencial para que elementos até então dispersos se reúnam para formar uma paisagem, e, por outro lado, sendo que a paisagem só possui Stimmung a partir do momento em que os elementos já estão reunidos de modo a formar uma paisagem, o que vem primeiro, a Stimmung ou a unidade perceptível? A resposta, para Simmel (1988), é que não há entre estes dois termos nenhuma relação 
de causa e efeito, ou seja, eles ocorrem simultaneamente. As consequências metodológicas desta conclusão são significativas, pois dela derivam abordagens recentes que veem a paisagem a meio caminho entre sujeito e objeto: "[...] a paisagem não reside nem somente no objeto, nem somente no sujeito, mas na interação complexa destes dois termos." (BERQUE, 1994, p. 5).

Ritter (1997, p. 61), por sua vez, associa a criação da paisagem à "[...] necessidade de uma verdade mediada pela estética [...]" para vencer a separação que uma nova ideia de natureza, uma "[...] natureza 'objetiva' separada do contexto da existência e da intuição [...]" provocou a partir da modernidade. $\bigcirc$ progresso das ciências, particularmente daquelas voltadas ao conhecimento da natureza, só foi possível com a transformação da natureza em objeto e o consequente divórcio entre ela e o homem. No entanto, deste estágio em diante, nem a ciência e nem o conceito racional podiam mais propiciar a "[...] presença da natureza em sua totalidade [...]" (RITTER, 1997, p. 61). A paisagem, como experiência estética, vem preencher esta lacuna:

Opondo-se assim ao mundo objetual que as ciências naturais subtraíram ao conceito metafísico, a natureza estética, a paisagem, fica encarregada de comunicar ao homem, por meio de imagens "vivas" e saídas da interioridade, o todo natural, "a harmonia reinante no cosmos" e de lhes conferir uma presença estética. (RITTER, 1997, p. 65).

Referindo-se a Humboldt, continua Ritter:

Para pintar a natureza em toda sua grandeza não se deverá então ficar simplesmente nos fenômenos exteriores; será preciso também representar a natureza tal como ela se reflete na interioridade dos homens [...] (HUMBOLDT, 1845-1862 apud RITTER, 1997, p. 65).

Novamente, aqui, o interior e o exterior, o sujeito e o objeto, se fundem para gerar a paisagem.

Por fim, outro texto que traz contribuições fundamentais nesta direção é $\mathrm{O}$ homem e a Terra, escrito por Eric Dardel em 1952. Dardel, que trata antes de tudo da experiência primordial e imediata de existir na Terra, nem sempre usará a palavra paisagem (tampouco estética), embora a ela dedique o título de um dos tópicos que compõem o capítulo primeiro do livro. Para ele, "[...] a paisagem não é, em sua essência, feita para ser vista, mas inserção do homem no mundo [...]" (DARDEL, 1990, p. 44). No entanto, é interessante observar como Dardel (1990, p. 41), sem citá-la, remete à Stimmung de Simmel (1998), ao afirmar que numa paisagem "[...] um vínculo interno, uma 'impressão' une todos os elementos." Para Dardel (1990, p. 44), "[...] há, na paisagem, um rosto, um olhar, uma escuta [...]". A mesma matéria deste tópico - os sentimentos, os afetos, as vivências, a indispensável presença humana, "[...] mesmo onde ela toma a forma da ausência [...]" - é instilada por todo o livro. Assim, mesmo quando não profere a palavra, é também da paisagem que ele fala. 
Escritos em momentos diferentes, com tônicas distintas, pode-se dizer, em resumo, que estes três textos, sumariamente expostos, têm em comum o voltar-se à experiência estética (em sentido amplo) da paisagem e às suas "tonalidades afetivas", existenciais. Os comentários sobre eles poderiam e mereceriam ser estendidos, mas não é este o objetivo destas páginas, e sim o de convidar a uma leitura que poderá dar um novo alento ao ensino, à pesquisa e às intervenções paisagísticas. Os seus rebatimentos, com certeza, não são diretos, imediatos, mas pode-se aventar que sua consideração nos métodos de ensino e no próprio ato projetual redunde em ganhos substanciais nos sentidos atribuídos ao fazer paisagístico.

\section{REFERÊNCIAS BIBLIOGRÁFICAS}

BERQUE, Augustin (Dir.). Cinq propositions pour une théorie du paysage. Seyssel: Editions Champ Vallon, 1994.

BESSE, Jean-Marc. Ver a Terra: seis ensaios sobre a paisagem e a geografia. Tradução de Vladimir Bartalini. São Paulo: Perspectiva, 2006.

CULLEN, Gordon. Townscape. London: The Architectural Press, 1961.

DARDEL, Eric. L'homme et la Terre: nature de la réalité géographique. Paris: Éditions du CTHS, 1990.

DOURADO, Guilherme Mazza. Belle époque dos jardins. São Paulo: Editora Senac, 2011.252 p.

ECKBO, Garrett. Landscape for living. New York: F. W. Dodge Corporation, 1950.

The art of home landscaping. New York: McGrow Hill, 1956.

Urban landscape design. New York: McGrow Hill, 1964.

The landscape we see. New York: McGrow Hill, 1969.

FORESTIER, Jean Claude Nicolas. Grandes villes et systems de parcs. Paris: Éditions Norma, 1997.

LE CORBUSIER. Urbanisme. Paris: Les Éditions G. Crés \& Cie, 1925.

A Carta de Atenas. Tradução de Rebeca Scherer. São Paulo: Edusp-Hucitec, 1993. Não paginado.

A viagem do Oriente. São Paulo, Cosac Naify, 2011 , (1ª reimpressão).

LYNCH, Kevin. A imagem da cidade. Tradução de Jefferson Luiz Camargo. São Paulo: Martins Fontes, 1997.

McHARG, lan L. Design with nature. New York: Natural History Press, 1969.

MORAES, Antonio Carlos Robert de. Geografia: pequena história crítica. 3 ed. São Paulo: Hucitec, 1984.

MUNFORD, Lewis. The social function of open spaces. In: Landscape, v. 10, n. 2, 1960-1961.

RIBEIRO, Rafael Winter. Paisagem cultural e patrimônio. Rio de Janeiro: IPHAN, 2007.

RITTER, Joachim. Paysage: fonction de l'esthétique dans la société moderne. Besançon: Les Éditions de l'Imprimeur, 1997.

SANTOS, Milton. A natureza do espaço. 4 ed. São Paulo: Edusp, 2002.

SCHERER, Rebeca. Introdução. In: LE CORBUSIER. A Carta de Atenas. Tradução de Rebeca Scherer. São Paulo: Hucitec-Edusp, 1993. Não paginado.

SIMMEL, Georg. Philosophie du paysage. In: La tragedie de la culture. Paris: Editions Rivages, 1988.

SITTE, Camillo. A construção das cidades segundo seus princípios artísticos. São Paulo: Ática, 1994.

TUAN, Yi-Fu. Topofilia: um estudo da percepção, atitudes e valores do meio ambiente. São Paulo: Difel, 1980.

VIDAL DE LA BLACHE, Paul de. Tableau de la géographie de la France. Paris: Librairie Hachette, 1908. 